\title{
O CONTEXTO SOCIO-HISTÓRICO DA EMERGÊNCIA E DESENVOLVIMENTO DOS PTRC NA AMÉRICA LATINA E CARIBE ${ }^{1}$
}

\author{
Valéria Ferreira Santos de Almada Lima
}

Universidade Federal do Maranhão (UFMA)

\begin{abstract}
O CONTEXTO SOCIO-HISTÓRICO DA EMERGÊNCIA E DESENVOLVIMENTO DOS PTRC NA AMÉRICA LATINA E CARIBE

Resumo: Este artigo resulta do Projeto de Pesquisa intitulado Programas de Transferência de Renda Condicionada na América Latina: estudo comparado - Bolsa Família (Brasil), Nuevo Régimen de Asignaciones Familiares - AFAM-PE (Uruguai) e Asignación Universal por Hijo (Argentina), financiado pela Capes e CNPq. Objetiva analisar o contexto sociohistórico que ensejou a emergência e o desenvolvimento dos PTRC, como estratégia privilegiada de enfrentamento à pobreza na atualidade. Aborda, para tanto, as transformações experimentadas pelo sistema capitalista mundial a partir do final da década de 1960, com foco nas mudanças no padrão de regulação econômica e social do capitalismo, inspiradas na ideologia neoliberal. Em seguida, discute os rebatimentos e as especificidades de tais mudanças na região da América Latina e Caribe, com vistas a identificar os principais determinantes da inclusão de tais programas nos Sistemas de Proteção Social da grande maioria dos países latino-americanos a partir dos anos 1990.
\end{abstract}

Palavras-chave: Contexto sócio-histórico, Programas de Transferência de Renda Condicionada, América Latina e Caribe.

\section{THE SOCIO - HISTORICAL CONTEXT OF EMERGENCY AND OF PTRC DEVELOPMENT IN LATIN AMERICA AND} THE CARIBBEAN

Abstract: This article results of the research project entitled Conditional Income transfer Programs in Latin America: a comparative study between Bolsa Família (Brazil), Régimen de Asignaciones Familiares - AFAM-PE (Uruguay) and Asignación Universal por Hijo (Argentina), supported by Capes and CNPq. It aims to analyze the socio-historical context that gave rise to the emergence and development of the PTRC, as a privileged strategy to confront poverty today. Addresses, therefore, the changes experienced by the world capitalist system since the end of the 1960s, focusing on changes in the pattern of economic and social regulation of capitalism, inspired by neoliberal ideology. Then, this article discusses the repercussions and the specifics of such changes in the Latin American and Caribbean region, in order to identify the main determinants of the inclusion of such programs in the system of social protection of most Latin American countries since 1990s.

Key words: Socio - historical Context, Conditional Income Transfer Programs, Latin America and the Caribbean. 


\section{INTRODUÇÃO}

O presente texto se constitui em um dos produtos resultantes de um Estudo Exploratório acerca dos Programas de Transferência de Renda Condicionada (PTRC) em desenvolvimento na região da América Latina e Caribe, o qual, por seu turno se situa no âmbito de um Projeto de Pesquisa financiado pela Coordenação de Aperfeiçoamento de Pessoal de Nível Superior (CAPES) e pelo Conselho Nacional de Desenvolvimento Científico e Tecnológico (CNPq), intitulado Programas de Transferência de Renda Condicionada na América Latina: estudo comparado - Bolsa Família (Brasil), Nuevo Régimen de Asignaciones Familiares AFAM-PE (Uruguai) e Asignación Universal por Hijo (Argentina).

Isso posto, a reflexão aqui desenvolvida tem como objetivo central analisar o contexto socio-histórico que ensejou a emergência e o desenvolvimento dos PTRC, como estratégia privilegiada de enfrentamento à pobreza na atualidade. Assim sendo, em primeiro lugar, aborda as transformações experimentadas pelo sistema capitalista mundial a partir do final da década de 1960, em resposta a mais uma crise estrutural do capital destacando especialmente as mudanças no padrão de regulação econômica e social do capitalismo, inspiradas na ideologia neoliberal. Em seguida, discute os rebatimentos e as especificidades de tais mudanças na região da América Latina e Caribe, consubstanciadas no ajuste estrutural e desencadeadas a partir do Consenso de Washington, com vistas a identificar os principais determinantes da inclusão de tais programas nos Sistemas de Proteção Social da grande maioria dos países latino-americanos a partir dos anos 1990.

\section{REESTRUTURAÇÃO CAPITALISTA E MUDANÇAS NO PADRÂO DE REGULAÇÃO}

A partir do final da década de 1960, a economia capitalista mundial experimentou uma inflexão cujos sintomas mais evidentes foram a desaceleração da taxa de crescimento do produto industrial, a retração do valor do comércio internacional e uma concomitante e extraordinária expansão financeira. Esta última, na visão de Arrigh (1996), embora não tenha representado uma novidade no desenvolvimento do capitalismo, sobretudo em momentos de acirramento da concorrência, assumiu uma dimensão e uma sofisticação técnica sem precedentes na história desse sistema de produção, pondo em xeque a própria autonomia dos Estados Nacionais no que tange à gestão da moeda e da força de trabalho, além de repercutir negativamente sobre o mercado de trabalho.
Tais manifestações expressaram mais uma crise estrutural do capital, ocasionada pela queda da taxa de lucro, em um contexto de acirramento da concorrência intercapitalista em âmbito mundial e de esgotamento do paradigma produtivo e tecnológico taylorista-fordista para fazer face às exigências de elevação da produtividade e de adequação aos novos padrões de competitividade.

Nesse contexto e em resposta à crise, assistiu-se a um conjunto de transformações que extrapolaram a base produtiva e atingiram as demais esferas da sociedade, dando conformação a um processo de reestruturação capitalista em escala global. Com efeito, em substituição ao regime fordista de acumulação, ganhou espaço um regime de acumulação flexível, cujas implicações foram muito além da introdução de inovações tecnológicas e organizacionais nas unidades básicas que compõem a estrutura do sistema capitalista, afetando o padrão dominante de regulação econômica e social e a própria forma de organização do Estado. Tudo isso favorecido por um contexto político marcado pelo fim da Guerra Fria e ascensão ao poder de partidos e governos conservadores nos países capitalistas centrais, abrindo espaço para a disseminação e aplicação do pensamento neoliberal (LIMA, 2002).

Particularmente no que tange ao padrão de regulação econômica e social, enquanto no Welfare State Keynesiano, que deu sustentação ao regime fordista de acumulação, o objetivo central era a geração de emprego em economias nacionais relativamente fechadas, na nova forma assumida pelo Estado, denominada por Jessop (1991) de Workfare State Shumpteriano, o foco se deslocou para a promoção da inovação dos produtos, dos processos de organização e dos mercados, com vistas à competitividade estrutural de economias abertas, a partir de mecanismos de intervenção econômica que priorizam o lado da oferta e não mais o da demanda, como no Welfare State Keynesiano.

Tal mudança de orientação se traduziu, no plano econômico, em primeiro lugar, em uma série de medidas que enfatizaram a estabilização monetária e o equilíbrio orçamentário, em detrimento da geração de emprego, traduzidas, dentre outras, na privatização de empresas estatais e na redução dos gastos públicos, sobretudo na área social. Em segundo lugar, mas não menos importante, sobressaiu o reforço à competitividade e à inserção da economia nacional na nova ordem mundial globalizada, por meio de medidas tais como: a desregulamentação dos mercados, a redução e a flexibilização dos custos trabalhistas, dentre outras (LIMA, 2002).

Por outro lado, no plano social, o novo padrão de regulação estatal substituiu as políticas de integração de cunho universalista e distributivo pelas chamadas políticas de inserção, de caráter residual, focalizadas nos segmentos sociais mais vulneráveis. Segundo Castel (1998), as primeiras, tendo como objetivo a homogeneização da sociedade a partir do centro, compreendiam ações voltadas para a ampliação do acesso aos serviços públicos, a 
redução das desigualdades, o desenvolvimento das proteções e a consolidação da condição salarial. Já as segundas visam a reduzir o déficit de integração dos segmentos mais vulneráveis, pautando-se na lógica da discriminação positiva, cujo horizonte é a promoção da igualdade de oportunidades tão cara à tradição liberal (LIMA, 2008).

Dentre as políticas de inserção merecem aqui destaque os PTRC também denominados de Programas de Renda Mínima, os quais, no contexto europeu, se desenvolveram em três momentos, conforme destaca Stein (2009) baseada em uma periodização estabelecida por Ayala (2000): em um primeiro momento emergiram as experiências pioneiras no bojo da fase expansiva do modelo de acumulação europeu, como parte do processo de expansão dos Estados de Bem-Estar modernos, em países como Dinamarca, Áustria, Suécia, dentre outros. Em um segundo momento, as experiências assumiram um caráter emergencial para fazer face à eclosão da crise econômica. O terceiro momento, iniciado em meados dos anos 1980, foi marcado pela evolução dos Programas de Renda Mínima para as chamadas Rendas Mínimas de Inserção (RMI), as quais associaram a garantia de renda ao apoio público para facilitar a inserção dos beneficiários no mercado de trabalho.

\section{A REGIÃO DA AMÉRICA LATINA E CARIBE SOB O IMPACTO DO AJUSTE ESTRUTURAL DOS ANOS 1990}

Centrando o foco da análise especificamente na região da América Latina e Caribe, objeto da presente reflexão, a crise mundial iniciada em fins dos anos 1960, as grandes transformações societárias ocorridas ao longo dos anos 1970 e seguintes, no contexto do processo de globalização dos mercados e mundialização do capital, a crise da dívida externa e a presença de vigorosos desequilíbrios macroeconômicos na região, na década de 1980, impuseram, sob a regência dos países centrais e de agências multilaterais, a adoção de novas medidas de gestão da política econômica por parte dos países periféricos.

Foi nessa perspectiva que o Fundo Monetário Internacional (FMI) e o Banco Interamericano de Desenvolvimento (BIRD) reordenaram suas funções e iniciaram uma nova postura junto aos países do antigo Terceiro Mundo, como instituições balizadoras da gestão e da coordenação das novas políticas econômicas mundiais. Consolidou-se e generalizouse uma nova estratégia econômica para a periferia capitalista e para todos os que deixaram de ser países em desenvolvimento para se transformarem em mercados emergentes (FIORI, 1998).

Em vista disso, o ajuste estrutural teve como uma de suas características centrais: legar maior importância ao papel dos mecanismos de mercado e por consequência do setor privado; redefinir o papel do Estado na sua ação interventora; e, integrar os países periféricos, nesse caso, os da América Latina na economia mundial.

As reformas contidas nos planos de ajuste estrutural marcaram a implantação de um novo modelo de desenvolvimento econômico efetivado pelos governos da América Latina, sobretudo nos anos 1990. Assim, "[...] chegava à periferia capitalista endividada e em particular à América Latina uma versão adaptada das idéias liberal-conservadoras." (FIORI, 1998, p. 121-122).

As orientações de políticas econômicas visando e projetando o ajuste para a América Latina encontram-se bem definidas no documento denominado Consenso de Washington ${ }^{2}$, o qual foi respaldado por organismos internacionais e pelos países centrais, controladores da globalização. Nesse documento, consta a série de reformas que as economias estatizadas da América Latina deveriam aplicar para atrair novamente os capitais privados depois da arrasadora crise da dívida dos anos 1980, a década perdida como ficou registrada na literatura.

O Consenso tinha como intento, através de uma proposta de política econômica, desencadear as necessárias mudanças, através de: (a) um pacote de reformas estruturais, comportando a liberalização da conta corrente do balanço de pagamentos e de sua conta de capitais, a desregulamentação dos controles de preços na economia (particularmente, salários, taxas de juros e taxa de câmbio) e a privatização de áreas importantes da atividade produtiva; e (b) de políticas macroeconômicas de estabilização, com o objetivo de superar a crise da dívida externa, eliminando os desequilíbrios econômicos, com alto déficit e alta inflação (WILLIAMSON; KUCZYNSKI, 2004).

Em síntese, o conjunto de políticas implantado na região, ao longo dos anos 1990 pode, concisamente, ser dividido em três ordens de proposições. A primeira era relativa às políticas macroeconômicas, com recomendação de uma intensa austeridade fiscal e disciplina monetária, articulada a um programa de corte nos gastos públicos, além de reformas administrativas, previdenciárias e fiscais. A segunda, atinente a políticas microeconômicas, colocava a necessidade de desonerar o capital, na perspectiva de que, assim, aumentaria sua competitividade em um mercado internacional aberto e desregulado. Para isso, era imprescindível que as empresas dos países periféricos entrassem no jogo global, sendo obrigatório expô-las à competição internacional aberta, o que demandava suprimir políticas de proteção e subsídio. O entendimento era de que isso seria constituído "[...] com a diminuição dos encargos sociais e a racionalização das intervenções nos sistemas de crédito público e fiscal." (FIORI, 1998 , p. 85). A terceira mencionava a necessidade 
de mudança radical no modelo de industrialização pautado na substituição de importações, adotado pela maioria dos países da região desde meados dos anos 1950, o que permitiria a retomada dos investimentos e do crescimento econômico.

A reestruturação inspirada no pensamento neoliberal teve importantes conseqüências na região da América Latina e Caribe. Sempre considerando as especificidades de cada país, não resta dúvida que os processos de privatização, ajuste fiscal, flexibilização da relação capital-trabalho, abertura dos mercados e deterioração dos recursos naturais e energéticos bem como dos serviços públicos provocaram impactos significativos nos diferentes países da região, resumidos em uma crescente massa da população em condições de pobreza e na precarização do trabalho.

Com efeito, a América Latina fechava o século $X X$ com quase a metade da sua população em situação de pobreza, e sendo considerada uma das regiões mais desiguais do mundo: em 1999, $43,4 \%$ da população latino-americana se encontrava em situação de pobreza. Até inícios dos anos 2000 os momentos de crescimento econômico não só não implicaram progressos substantivos na redução da pobreza e da desigualdade como incidiram para - agravamento dos índices da extrema pobreza (COMISSÃO ECONÔMICA PARAAMÉRICA LATINA E O CARIBE, 2012).

De fato, durante a década de 1990, as políticas de ajuste neoliberal na América Latina, superpostas à herança social acumulada histórica e estruturalmente, recrudesceram o quadro de crise social da região, com o aumento considerável das taxas de desemprego.

Entre 1990 e 2002 a taxa média do desemprego na América Latina tinha aumentado de $4,5 \%$ para $11,1 \%$. Com exceção do Chile, todos os países do Cone Sul ultrapassaram a taxa média de desemprego latino-americano em 2002. Paralelamente, segundo o Relatório da Organização Internacional do Trabalho (OIT), oito de cada dez postos de trabalho, criados nos anos 1990, correspondiam a ocupações de baixa qualidade no setor informal. Assim, ao histórico problema do desemprego estrutural na América Latina, somouse, na década de 1990, o aumento da precariedade e fragilidade das relações de trabalho (COMISSÃO ECONÔMICA PARA AMÉRICA LATINA E O CARIBE; ORGANIZAÇÃO INTERNACIONAL DO TRABALHO, 2011).

As mudanças no mercado de trabalho tiveram conseqüências profundas na proteção social. Isto porque, dadas as características dos Estados Sociais latinoamericanos, o trabalho remunerado e, em particular, o acesso ao emprego formal é o vínculo por excelência para o acesso à proteção social em matéria de seguridade social e, em menor medida, também em matéria de saúde.

A propósito, particularmente no que tange aos sistemas de proteção social latinoamericanos, as propostas e tendências centrais de orientação neoliberal impuseram uma modificação das políticas de proteção social em direção a uma perspectiva residual- liberal. Assim sendo, os sistemas de proteção social até então centralizados, setorializados, com aspiração de universalidade e administrados estatalmente, configurados no marco do modelo de substituição de importações, foram desestruturados e reformados por modelos de políticas sociais descentralizados, integrais, focalizados e com a ampliação de processos de privatização. Estes modelos de perspectiva liberal se apoiam na idéia de que é o mercado, através do crescimento económico e a teoría do derrame, quem cumprirá o papel fundamental de incorporação social. Este esquema se centra em intervir na pobreza e nos pobres, desarmando as relações inerentes ao modelo institucional de proteção social que institucionalizava garantias e direitos aos segmentos de trabalhadores organizados e formalizados. Desta forma, expressa uma das facetas da reação contra a organização da classe trabalhadora, que sofreu múltiplos embates através de processos de reestruturação produtiva, repressão política e crises econômicas nas últimas duas décadas do século $X X$.

$\mathrm{Na}$ primeira década do século XXI, verificaram-se na América Latina - com suas heterogeneidades e complexidades - algumas inflexões em relação às décadas finais do século $\mathrm{XX}$. Em um contexto de crescimento económico e de mudanças no campo político de diversos países da região, se registraram melhorias em alguns indicadores sociais, centralmente na pobreza, na indigência e nas taxas de desemprego.

Pela primeira vez em 20 anos, a partir de 2003, é possível apontar um processo de redução sistemática da pobreza e da indigência. Não só porque se alcançou, em 2012, uma redução de 15 e 7.2 pontos percentuais, respectivamente, em relação aos percentuais de 1999, mas também porque foi uma tendência observada em grande parte dos países da região. Entre 2002 e 2008 a redução da pobreza e da indigência tinha-se manifestado em praticamente todos os países (COMISSÃO ECONÔMICA PARA AMÉRICA LATINA E O CARIBE, 2012). Paralelamente, embora a América Latina continue sendo uma das regiões mais desiguais do mundo, após os anos 2002 a região vivenciou uma queda substancial nos índices de concentração de renda. Contrariamente ao aumento das desigualdades de renda dos anos 1990 até início dos 2000, a partir de 2002, o coeficiente de Gini, na região e em quase todos os países, vivenciou uma queda sistemática. Enquanto 11 de 18 países estudados tiveram aumento do coeficiente Gini durante o período de 1990 a 2002, de 2002 a 2008 a tendência foi a sua diminuição, com exceção da Guatemala e República Dominicana. Note-se, inclusive, que a melhora distributiva se manteve mesmo após as crises econômicas internacionais, 
de 2008. Dos 18 países estudados somente na República Dominicana, Paraguai e Equador a desigualdade teve um leve aumento, durante os anos de 2008 e 2010 (COMISSÃO ECONÔMICA PARA AMÉRICA LATINA E O CARIBE, 2011).

Entretanto, a América Latina, quando comparada a outras regiões do mundo, continua sendo uma das mais desiguais. Todas as regiões, excetuando a África subsaariana apresentam um coeficiente de Gini inferior ao latino-americano. Isto, porque apesar da queda das disparidades de renda, a desigualdade permanece como marca estrutural na região: a renda média do quintil mais rico é 18,3 vezes maior que a do quintil mais pobre (COMISSÃO ECONÔMICA PARAAMÉRICA LATINAE O CARIBE, 2012).

A melhoria dos indicadores de pobreza e desigualdade respondem, em parte ao crescimento econômico que teve como efeito positivo a geração de novos postos de trabalho. De fato, fases de crescimento do Produto Interno Bruto (PIB) similares na década anterior, não só não diminuíram como aumentaram as taxas de desemprego. O período entre 2003 e 2010 representa a primeira vez em duas décadas em que o desemprego diminuiu na América Latina e que os salários mínimos nacionais aumentaram. Quando se compara os períodos de 1991 a 1997 e de 2003 a 2010 é possível perceber uma tendência relativamente similar em termos de crescimento econômico (representada pelo PIB) e comportamentos inversos em termos da taxa de desemprego e da ocupação. Enquanto nos anos 1990 o desemprego aumentou e a taxa bruta de ocupação diminuiu, nos anos 2000, com o mesmo nível de crescimento, o desemprego diminuiu e a taxa de ocupação aumentou. Em termos de salários, a década de 2000 permitiu recuperar a perda do salário real acontecida nos anos 1990 e um aumento significativo dos salários mínimos nacionais.

Apesar do relativo aumento do emprego formal de trabalhadores assalariados que passaram de $65,2 \%$ em 1990 para $69 \%$ em 2010 e da queda relativa do percentual de trabalhadores nos setores de baixa produtividade e informalidade, que diminuiu de $48,1 \%$ em 1990 para $42,7 \%$ em 2009 , o setor de baixa produtividade continua sendo determinante na estrutura produtiva latino-americana, associado geralmente ao emprego de trabalhadores menos qualificados, com precária vinculação aos sistemas de previdência e baixos rendimentos.

Paralelamente a essas mudanças, sob a regência de setores de esquerda que ascenderam ao poder em vários países da região na década de 2000 , se observaram críticas às orientações das reformas neoliberais. Nesse contexto, passaram a coexistir dois enfoques gerais sobre política social: um relacionado com a competitividade sistêmica, em que conceitos como o de capital humano e o de transmissão intergeracional da pobreza ganham relevancia; outro vinculado ao enfoque de direitos e garantías de cidadania e sustentado nos pactos e tratados internacionais assumidos pelos Estados. Estes enfoques não são excludentes entre si, ainda que o segundo tenha alcançado maior visibilidade nos anos recentes (CECCHINI; MARTÍNEZ, 2011). Em termos de modelo de desenvolvimento, há um debate controvertido na literatura sobre a emergência de um novo padrão denominado de neodesenvolvimentismo.

Tal debate nasce mais precisamente no início do século $X X I$, em um contexto em que os países da América Latina, grande parte deles sob o comando de governos progressistas, oriundos de partidos de esquerda, vivenciavam uma inflexão marcada pela associação entre a retomada do crescimento econômico, favorecida por um contexto internacional favorável, e a melhoria dos indicadores sociais, sobretudo aqueles relacionados ao mercado de trabalho, à pobreza e à desigualdade.

Há que se reconhecer que todas essas mudanças expressas na melhoria dos indicadores sociais resultaram da retomada do crescimento econômico, acompanhada de políticas distributivas que possibilitaram a incorporação de parcela significativa da população latino-americana a novos padrões de consumo, promovendo, assim, a expansão e dinamização dos mercados internos. Dentre estas políticas, destacam-se os programas de transferência de renda e a valorização dos salários mínimos nacionais.

Mas essa importante e não desprezível inflexão experimentada pela maioria dos países latino-americanos seria suficiente para se vislumbrar a ruptura com o neoliberalismo e a emergência de um novo-desenvolvimentismo? Arrisca-se aqui a afirmar que não. Isto porque não mudou o sentido geral que orienta o padrão de regulação econômica e social do capitalismo no atual contexto de mundialização do capital, de financeirização da economia e de predomínio de um regime de acumulação flexível. Trata-se de assegurar as condições de flexibilidade necessárias ao atual processo de reorganização capitalista e compensar os efeitos perversos da globalização dos mercados e da busca de eficiência e de competitividade a qualquer preço (LIMA, 2008).

Pode-se depreender, portanto, que esse padrão de regulação em voga nos países capitalistas centrais a partir da virada dos anos 1970 para os 80 e apropriado pela periferia latino-americana, sobretudo, nos anos 1990 permanece intacto em sua essência quando comparado com a agenda proposta pelos ideólogos do novo-desenvolvimentismo, com algumas mudanças secundárias. Dentre estas se podem destacar: uma maior intervenção do Estado na economia, no sentido de corrigir as falhas do mercado, o que não significa necessariamente ruptura com os fundamentos centrais do neoliberalismo, já que, como ressalta Polanyi (1980), 
o liberalismo econômico e o intervencionismo estatal não são mutuamente excludentes; medidas de cunho distributivo e de ampliação do crédito ao consumo das famílias, com vistas à ampliação e dinamização do mercado interno, o que não se traduz em superação do caráter essencialmente residual e compensatório do padrão vigente de proteção social e nem em mudança na forma de repartição do fundo público, destinado prioritariamente para à remuneração das frações rentistas do capital.

Em realidade, é importante indicar que é a partir desse cenário que se prolifera na região a implantação de PTRC, cujo objetivo, nos discursos dos Chefes de Estado e de seus executivos e formuladores de políticas sociais, é o de erradicação da pobreza. No entanto, por detrás desse discurso é plenamente possível a percepção de que esses Programas são resultantes de imposições dadas por restrições de natureza interna e externa. As internas estão no alinhamento do gasto público estatal em razão da redefinição do papel do Estado e da governança macroeconômica exigida pelo ajuste estrutural, e, as externas estão materializadas nos compromissos firmados pelos Chefes de Estado tanto na I Cúpula das Américas, da Organização dos Estados Americanos (OEA), realizada no ano de 1994 em Miami, quanto nos Objetivos de Desenvolvimento do Milênio (ODM) ${ }^{3}$ para a região, estabelecidos em setembro de 2000 , sendo o principal a erradicação da pobreza.

\section{CONCLUSÃO}

A partir da reflexão desenvolvida neste texto, pode-se concluir que os PTRC, incorporados, a partir da década de 1990, aos Sistemas de Proteção Social da grande maioria dos países que integram a região da América Latina e Caribe, como estratégia privilegiada de enfrentamento à pobreza e às desigualdades sociais, resultam de um conjunto de transformações experimentadas pelo sistema capitalista em âmbito mundial e em especial no continente latino-americano.

Dentre estas transformações, destaca-se a mudança no sentido geral que orienta o padrão vigente de regulação econômica e social do capitalismo, cujo foco deixa de incidir na garantia do pleno emprego em economias nacionais parcialmente protegidas, passando a se centrar na garantia das condições de flexibilidade necessárias ao atual processo de reorganização capitalista e na compensação dos efeitos perversos da globalização e da busca de eficiência e de competitividade a qualquer custo. $\mathrm{O}$ rebatimento de tal mudança em termos do padrão dominante de Política Social é a substituição ou pelo menos a secundarização das políticas de cunho universalista em favor das políticas de caráter residual, focalizadas em populações e regiões mais vulneráveis.
A manifestação concreta dessas transformações no âmbito da região da América Latina e Caribe foi a implementação, sobretudo a partir da década de 1990, de um conjunto de reformas estruturais, inspiradas no Consenso de Washington e impostas pelos Organismos Financeiros Internacionais, com vistas a favorecer a inserção das economias da região à nova ordem mundial globalizada.

As consequências desse ajuste estrutural foram deletérias do ponto de vista dos indicadores de mercado de trabalho, pobreza e desigualdade, sobrepondo-se a uma realidade já historicamente marcada pela heterogeneidade estrutural, pela forte segmentação do mercado de trabalho e pelo predomínio de Sistemas de Proteção Social que não lograram a universalização de importantes direitos sociais, posto que tinham no trabalho remunerado e, em particular, no acesso ao emprego formal o requisito essencial para o direito à proteção social em matéria de seguridade e também, em certos casos, em matéria de saúde. De fato, apesar de melhorias não desprezíveis experimentadas pelos indicadores sociais da região a partir da primeira metade dos anos 2000, a pobreza e a desigualdade ainda persistem como marcas histórico-estruturais da região, a qual figura até hoje como uma das mais desiguais do mundo.

Foi, portanto, em um contexto de recrudescimento e de persistência da pobreza e das desigualdades sociais e de mudanças do padrão de regulação econômica e social que emergiram os PTRC, os quais foram incluídos na agenda dos governos eleitos entre as décadas de 1990 e 2000, muitos destes de tendências progressistas, como principal estratégia para fazerem cumprir os compromissos assumidos relativos aos ODM, dentre os quais se destaca a erradicação da pobreza.

Entretanto, convém aqui ressaltar que, diante das novas condições de acumulação do capitalismo globalizado e do padrão vigente de regulação, a característica mais marcante e perturbadora da atualidade é o desemprego. Ademais, considerandose especialmente o novo padrão de regulação econômica e social do capitalismo, inspirado na ideologia neoliberal, vale lembrar a afirmação de Gentili (1998, p. 89) segundo o qual

A garantia do emprego como direito social (e sua defesa como requisito para as bases de uma economia e uma vida política estável) desmanchou-se diante da nova promessa de empregabilidade como capacidade individual para desfrutar as limitadas possibilidades de inserção que o mercado oferece.

Inspirada na Teoria do Capital Humano ${ }^{4}$, revista e atualizada, sobretudo a partir da segunda metade dos anos 1980, a promessa da empregabilidade, de caráter essencialmente privado, recupera a concepção individualista da Teoria do 
Capital Humano em sua versão original. Entretanto, ela elimina o nexo que tal teoria estabelecia entre o desenvolvimento do capital humano individual e o capital humano social, já que o tão propalado incremento das capacidades individuais aumenta tão somente as condições de empregabilidade, estando a efetiva inserção no mercado de trabalho condicionada ao êxito ou fracasso de cada um (LIMA, 2008).

Portanto, dada a condição inimpregável de grande parte da população à qual se destinam os PTRC, assim como as demais políticas de inserção, e considerando-se seus limites para reintegrar segmentos sociais que são inintegráveis (face às novas exigências do mercado de trabalho e às especificidades do atual regime de acumulação), tais políticas vêm perdendo o seu pretenso caráter transitório para se tornarem permanentes.

Nesse sentido, finaliza-se este texto concordando-se com Castel (1998), segundo o qual a inserção propiciada por políticas dessa natureza deixa de representar uma etapa provisória, transformando-se em um Estado ou uma nova modalidade de existência social, situada entre a completa exclusão e a integração (LIMA, 2008).

\section{REFERÊNCIAS}

ARRIGH, G. O longo século XX. Rio de Janeiro: Contraponto; São Paulo: Editora UNESP, 1996.

CASTEL, R. As metamorfoses da questão social: uma crónica do salário. Petrópolis, RJ: Vozes, 1998.

CECCHINI, S.; MARTÍNEZ, R. Protección social inclusiva en América Latina: una mirada integral, un enfoque de derechos. Santiago de Chile: CEPAL, 2011.

COMISSÃO ECONÔMICA PARA AMÉRICA LATINA E O CARIBE. Panorama social de América Latina 2011. Santiago de Chile, Nações Unidas, 2011.

Panorama social de América Latina 2012: documento informativo. Santiago de Chile, Nações Unidas, 2012.

ORGANIZAÇÃO INTERNACIONAL DO TRABALHO. Coyuntura Laboral em América Latina y el Caribe: los programas de transferencia condicionadas y el mercado laboral. Santiago de Chile, 2011.

FIORI, J. L. (Orgs.). Poder e dinheiro: uma economia política da globalização. 6 ed., Petrópolis, RJ: Vozes, 1998, p. 87-150.

GENTILI, P. Educar para o desemprego: a desintegração da promessa integradora. In:
FRIGOTO, Gaudêncio (Org.). Educação e crise do trabalho: perspectivas do final do século. Petrópolis, RJ: Vozes, 1998.

JESSOP, B. Changing forms and functions of the State in na era of globalization and regionalization. [S. I.: s. n.], 1991. In: European Association for Evolutionary Political Economy, Paris, 1991. Paper... Paris, 1991.

LIMA, V. F. S. de A. Reforma do Estado e Controle Social: limites e possibilidades da descentralização e do terceiro setor. Revista de Políticas Públicas, São Luís, v. 6, n. 2, p. 2002.

V. F. S. de A. Apresentando referências de fundamentação das experiências de pesquisas avaliativas. In: SILVA, M. O. da S. e (Org.) Pesquisa Avaliativa: aspectos teórico-metodológicos. São Paulo: Veras Editora; São Luís: GAEPP, 2008.

POLANYI, K. A grande transformação. Rio de Janeiro: Campus, 1980.

STEIN, R. H. Configuração recente dos programas de transferência de renda na América Latina: focalização e condicionalidade. In: BOSCHETTI, I. et al. (Orgs.). Política social no capitalismo: tendências contemporâneas. 2. ed. São Paulo: Cortez, 2009.

WILLIAMSON, J.; KUCZYNSKI, P. P. Depois do Consenso de Washington: retomando o crescimento e a reforma na América Latina. São Paulo: Saraiva, 2004.

\section{NOTAS}

Esse artigo, apresentado na VII Jornada Internacional de Políticas Públicas (JOINPP), São Luís, 25 a 28 de agosto de 2015, contém resultados parciais de estudos desenvolvidos com o apoio da CAPES e do $\mathrm{CNPq}$, entidades do Governo brasileiro, voltadas para a formação dos recursos humanos e a pesquisa.

2 Entende-se que o Consenso de Washington "[...] condensava e traduzia as idéias neoliberais, já hegemônicas nos países centrais, na forma de um pacote terapêutico para a 'crise econômica' da periferia capitalista." (FIORI, 1998, p. 84). O Consenso concretizou-se com aprovação e respaldo do Tesouro dos EUA e de instituições com reconhecimento público quanto a seu vínculo com o capital hegemônico internacional (FMI, Banco Mundia (BM), BIRD e Organização Mundial do Comércio (OMC)).

3 Os ODM foram fixados para o período 1990-2015. Ao todo são oito objetivos, abrangendo desde a erradicação da pobreza e preocupações como ensino, saúde e igualdade de gênero até aspectos relacionados ao meio ambiente e ao estabelecimento de uma aliança mundial para o desenvolvimento. $\mathrm{O}$ alcance está associado à execução de 18 metas, divididas em 48 indicadores 
(COMISSÃO ECONÔMICA PARA AMÉRICA LATINA E O CARIBE, 2005).

4 A Teoria do Capital Humano, uma das mais importantes referências teóricas da economia da educação, despontou nos anos 1950-60, tendo como pressuposto o de que o Estado, ao investir na promoção de políticas planejadas de educação e formação de mão-de-obra, estaria contribuindo, por um lado, para o aumento da renda individual (derivada do incremento do capital humano individual) e, por outro, para o aumento da riqueza social (derivada do incremento do capital humano social).

\section{Valéria Ferreira Santos de Almada Lima}

\section{Economista}

Doutora em Políticas Públicas pela Programa de Pós-Graduação em Políticas Públicas (PPGPP) da Universidade Federal do Maranhão (UFMA)

Professora do Departamento de Economia e do PPGPP da Universidade Federal do Maranhão (UFMA)

E-mail: valmadalima@gmail.com

\section{Universidade Federal do Maranhão - UFMA}

Cidade Universitária Dom Delgado

Av. dos Portugueses, n. 1966, Bacanga, São Luís/MA 